\title{
Does the internal thoracic artery graft have self-reparative ability?
}

Soichiro Kitamura, MD

See related article on page 1661.
From the National Cardiovascular Center, Osaka, Japan.

Received for publication Aug 16, 2005; accepted for publication Aug 22, 2005.

Address for reprints: Soichiro Kitamura, MD, National Cardiovascular Center, 5-7-1 Fujishirodai, Suita, Osaka 565-8565, Japan (E-mail: skitamur@hsp.ncvc.go.jp).

J Thorac Cardiovasc Surg 2005;130:1494-5

$0022-5223 / \$ 30.00$

Copyright (C) 2005 by The American Association for Thoracic Surgery

doi:10.1016/j.jtcvs.2005.08.030
1 ccumulating clinical $^{1-3}$ and basic $^{4,5}$ evidence with regard to the internal thoracic artery (ITA) as a viable graft has revealed that this arterial graft for coronary bypass surgery is not a simple conduit to transport blood to the myocardium. It has a character of the major collateral pathway ${ }^{6}$ with active biologic potency, such as immunity from the atherosclerotic process, active dilatation and resultant arterial wall remodeling, excellent endothelial secretion of nitric oxide and other biologically active substances, active thinning (string phenomenon) with no-flow patency (nonworking collateral vessel), reestablishment of graft flow depending on the myocardial demand, and the phenomenon that we can call the "self-reparative ability," as published in this issue of the Journal. ${ }^{7}$

It has previously been demonstrated that the ITA graft can grow in longitudinal length and transverse diameter in response to somatic growth of children with coronary obstruction. ${ }^{8}$ This is the most clear-cut evidence to show that the ITA graft is a viable structure. Moreover, the ITA graft caliber at the anastomotic junction can also grow in children. ${ }^{9}$ Probably the same mechanism can work on the stenotic anastomotic sites in adults, with resultant late reduction in the grade of anastomotic stenosis located between the ITA graft and the recipient coronary artery, as shown in the article by Izumi and colleagues. ${ }^{7}$ Within 14 days after a bypass operation, ITA flow can show a several-fold increase with a 1.5 times increase in diameter. ${ }^{10}$ The ITA graft responds to an acute increase in flow by vasodilatation most importantly by release of nitric oxide, a potent vasodilator derived from the highly active endothelium of the ITA $^{11}$ induced by increased shear stress to the arterial wall. Shear stress-induced nitric oxide release occurs in a matter of several seconds through the calcium-dependent constitutive form of nitric oxide synthase activation. $^{12}$ The ITA graft can maintain the secretory ability of nitric oxide long after the bypass operation. ${ }^{13,14}$ Nitric oxide is released bidirectionally by the endothelium. ${ }^{15}$ Extraluminal nitric oxide acts on the underlying vascular smooth muscle regulating the vascular tone and inhibits neointimal proliferation. This action might be effective in making anastomotic stenoses less fibrotic. Intraluminal nitric oxide is released into the blood stream and can be demonstrated long after the bypass operation through activation of the ITA endothelium with acetylcholine. ${ }^{13}$ Intraluminally released nitric oxide protects platelet aggregation and adhesion and might have a metabolic effect on the downstream vascular beds. ${ }^{16}$ In this sense I think we can call ITA grafting autologous transplantation of the good-quality arterial endothelium into the coronary circulation that has impaired endothelial function with atherosclerosis. ${ }^{13}$ Excellent nitric oxide production of the ITA endothelium will prevent further atherosclerotic process for both grafts and grafted coronary arteries, and as a matter of fact, atherosclerotic progression of the coronary artery distal to the ITA graft anastomosis is infrequent. ${ }^{17}$ In addition, following revascularization with ITA grafts, coronary vasospastic response to ergonovine is significantly ameliorated or disappears at the segment distal to the ITA graft anastomosis. This phenomenon has been documented by angiography with pharmacologic intervention $^{18}$ and can be considered as a proof of the beneficial metabolic effect of the ITA graft, that is an antispastic effect of the ITA graft on vasospastic coronary arteries.

ITA grafts act differently from vein grafts on progression of grafted coronary artery stenosis proximal to the anastomosis. Angiographic progression of grafted coronary artery stenosis is $18 \%$ for ITA grafts versus $46 \%$ for vein grafts in one 
series, ${ }^{3}$ and $26 \%$ versus $45 \%,{ }^{19} 12 \%$ versus $38 \%,{ }^{20}$ and $39 \%$ versus $67 \%{ }^{17}$ in other series. These differences are all statistically significant. Progression occurs less frequently in coronary arterial segments bypassed with ITA grafts than in those bypassed with vein grafts. This fact is believed to be attributed to characteristics of the viable ITA graft's function as a major collateral channel. On the basis of these facts, I believe that the ITA graft has a potential metabolic effect that protects the grafted coronary arteries from vasospastic responses and atherosclerotic progression, resulting in longer survival of the patients with more ITA grafts than those without ITA grafts. ${ }^{21}$ This salutary metabolic effect of the ITA graft cannot be expected from coronary stents alone. In the present article by Izumi and colleagues, ${ }^{7}$ the physiologic response and adaptability of the ITA graft is again demonstrated in terms of the self-reparative ability that can be expected only in a viable graft.

This article also gives rise to an important clinical issue, particularly in the era of off-pump coronary artery bypass, during which anastomotic complications possibly increase. The issue is whether early postoperative angiographic confirmation is needed more than before in the off-pump coronary artery bypass era. Early postoperative angiographic assessment is rather common in Japan but not so in Western counterparts, mainly because of the difference in social insurance coverage. According to the present report, early postoperative angiography is not necessary for the purpose of evaluating ITA graft anastomosis unless the patient shows some types of myocardial ischemia. In addition, intraoperative measurements and evaluation of graft flow with its pattern analysis can provide relatively accurate clues to detect anastomotic failure during an operation. With this technology, surgeons can handle it inside the operating room. In other words, as long as the ITA is adequately handled and anastomosed in the operating room, there is not much to worry about with regard to ITA graft status thereafter. This is certainly good information for surgeons. Also, cardiologists who perform early angiography for the purpose of their own confirmation and sometimes evaluation of surgeons should also realize this fact. However, when a tight (>80\%-90\%) anastomotic stenosis is found at angiography performed for any reason, I believe that balloon dilatation should be applied because this procedure is safe and long lasting ${ }^{22}$ and might prevent the ITA graft occlusion (thrombosis) that occurs at the rate of a few percent, usually as a result of some technical mishap. Simple balloon dilatation is quite satisfactory, with no need for stenting.

\section{References}

1. Cosgrove DM, Loop FD, Saunders CL, Lytle BW, Kramer JR. Should coronary arteries with less than fifty percent stenosis be bypassed? J Thorac Cardiovasc Surg. 1981;82:520-30.

2. Barner HB. Remodeling of arterial conduits in coronary grafting. Ann Thorac Surg. 2002;73:1341-5.
3. Kitamura S, Kawachi K, Morita R, Kobayashi H, Nishii T, Taniguchi $\mathrm{S}$, et al. Results of internal mammary artery-coronary artery bypass surgery and the characteristics of internal mammary artery grafts. Jpn Circ J. 1987;51:1052-60.

4. Ignarro LJ, Buga GM, Wood KS, Byrns RE, Chaudhuri G. Endotheliumderived relaxing factor produced and released from artery and vein is nitric oxide. Proc Natl Acad Sci U S A. 1987;84:9265-9.

5. Lüscher TF, Diederich D, Siebenmann R, Lehmann K, Stulz P, von Segesser L, et al. Difference between endothelium-dependent relaxation in arterial and venous coronary grafts. $N$ Engl J Med. 1988;319: 462-7.

6. Kitamura S, Kawachi K, Seki T, Sawabata N, Morita R, Kawata T. Angiographic demonstration of no-flow anatomical patency of internal thoracic-coronary artery bypass grafts. Ann Thorac Surg. 1992;53: 156-9.

7. Izumi C, Hayashi $\mathrm{H}$, Ueda $\mathrm{Y}$, Matsumoto M, Himura $\mathrm{Y}$, Gen $\mathrm{H}$, et al. Late regression of left internal mammary artery graft stenosis at the anastomotic site without intervention therapy. J Thorac Cardiovasc Surg. 2005;130:1661-7.

8. Kitamura S, Seki T, Kawachi K, Morita R, Kawata T, Mizuguchi T, et al. Excellent patency and growth potential of internal mammary artery grafts in pediatric coronary artery bypass surgery. New evidence for "live" conduit. Circulation. 1988;78(suppl I):I129-39.

9. Kitamura S, Kawachi K, Seki T, Morita R, Nishii T, Mizuguchi K, et al. Bilateral internal mammary artery grafts for coronary artery bypass operation in children. J Thorac Cardiovasc Surg. 1990;99:708-15.

10. Tagusari O, Kobayashi J, Bando K, Niwaya K, Nakajima H, Ishida M, et al. Early adaptation of the left internal thoracic artery as a blood source of Y-composite radial artery grafts in off-pump coronary artery bypass grafting. Heart Surg Forum. 2003;6:522-7.

11. He GW, Liu ZG. Comparison of nitric oxide release and endotheliumderived hyperpolarizing factor-mediated hyperpolarization between human radial and internal mammary arteries. Circulation. 2001;104: $1344-9$.

12. Kanai AJ, Strauss HC, Truskey GA, Crews AL, Grunfeld S, Malinski T. Shear stress induces ATP-independent transient nitric oxide release from vascular endothelial cells, measured directly with a porphyrinic microsensor. Circ Res. 1995;77:284-93.

13. Nishioka H, Kitamura S, Kameda Y, Taniguchi S, Kawata T, Mizuguchi K. Difference in acetylcholine-induced nitric oxide release of arterial and venous grafts in patients after coronary bypass operations. J Thorac Cardiovasc Surg. 1998;116:454-9.

14. Kushwaha SS, Bastami M, Tadjkarimi S, Ilsley CDJ, Mitchell AG, Yacoub MH. Late endothelial function of free and pedicled internal mammary artery grafts. J Thorac Cardiovasc Surg. 1995; 110:453-62.

15. Moncada S, Palmer RMJ, Higgs EA. Nitric oxide: physiology, pathophysiology and pharmacology. Pharmacol Rev. 1991;43:109-42.

16. Kalm M, Schrader J. Control of coronary vascular tone by nitric oxide. Circ Res. 1990;66:1561-75.

17. Loop FD. Internal-thoracic-artery grafts. Biologically better coronary arteries. N Engl J Med. 1996;334:263-5.

18. Kitamura S, Morita R, Kawachi K, Iioka S, Saki T, Inoue K, et al. Different responses of coronary artery and internal mammary artery bypass grafts to ergonovine and nitroglycerin in variant angina. Ann Thorac Surg. 1989;47:756-60.

19. Manninen HI, Jaakkola P, Suhonen M, Rehnberg S, Vuorenniemi R, Matsi PJ. Angiographic predictors of graft patency and disease progression after coronary artery bypass grafting with arterial and venous grafts. Ann Thorac Surg. 1998;66:1289-94.

20. Hamada Y, Kawachi K, Yamamoto T, Nakata T, Kashu Y, Watanabe $\mathrm{Y}$, et al. Effects of coronary artery bypass grafting on native coronary artery stenosis. J Cardiovasc Surg. 2001;42:159-64.

21. Lytle BW, Blackstone EH, Sabik JF, Houghtaling P, Loop FD, Cosgrove DM. The effect of bilateral internal thoracic artery grafting on survival during 20 postoperative years. Ann Thorac Surg. 2004;78: 2005-14.

22. Najm HK, Leddy D, Hendry PJ, Marquis JF, Richardson D, Keon WJ. Postoperative symptomatic thoracic artery stenosis and successful treatment with PTCA. Ann Thorac Surg. 1995;59:323-7. 